\title{
Public Service Motivation in the Chinese Public and Private Sectors
}

\author{
Dr. Dermot McCarthy (Corresponding Author) \\ Principal Lecturer in Economics. \\ Department of Accounting, Finance and Economics, \\ Bournemouth University, UK. \\ Email: dmccarthy@bournemouth.ac.uk \\ Telephone: +44 (0)1202968742
}

\section{Dr. Ping Wei}

Professor in Finance.

School of Business,

Central South University, China.

Email: pwei@csu.edu.cn

Telephone: +86 73188877723

\section{Dr Fabian Homberg}

Associate Professor HRM\&OB. Department of Business and Management

LUISS Guido Carli University, Rome

Email: fhomberg@luiss.it

Telephone: +390685798517

\section{Dr. Vurain Tabvuma}

Associate Professor in Management.

Sobey School of Business

Saint Mary's University,

B3H 3C3, Nova Scotia, Canada.

Email: vurain.tabvuma@smu.ca

Telephone: +1 (0) 9024205082 


\section{Introduction}

Although employees in both the public and private sectors are motivated by a combination of material incentives and intangible psychological rewards, those who are attracted to work in the public sector can be expected to attach more importance to helping others and display more altruistic tendencies, while placing relatively less emphasis on financial rewards (Anderfuhren-Biget et al., 2010). The idea of the public sector attracting workers who desire an opportunity to serve the public interest and influence public policy has given rise to research on public service motivation (PSM). Perry and Wise (1990, p.368) defined PSM as “individuals' predisposition to respond to motives grounded primarily or uniquely in public institutions and organisations". Common to most definitions of PSM is a desire to satisfy altruistic tendencies through working in the public interest and an active interest in public policy through service delivery (Kim, 2009b). PSM is usually assessed on four sub-dimensions, labelled by Perry (1996) as attraction to policy making, self-sacrifice, commitment to the public interest and compassion, although adaptations might be necessary for non-US samples (Kim et al., 2013). In the Chinese context, Liu et al. (2008) found evidence for three PSM dimensions (i.e. attraction to policy making, self-sacrifice and commitment to public interest).

A number of studies have compared the level of PSM across the public, private and non-profit sectors (Coursey et al., 2012, Sung Min and Word, 2012, Taylor, 2010, Word and Carpenter, 2013). These studies typically assume that the construct being measured has the same theoretical structure in each sector. Furthermore, they assume the measure being used, in this case the Perry (1996) measure or some variant of it, operates in the same way in each sector in terms of the potential relationship it has with workplace outcomes. To our knowledge, these two important assumptions have rarely been statistically tested for. An exception to this was Liu et al. (2012) who show measurement invariance among independent 
samples of Chinese public and private sector employees. However, their study provides a limited assessment of measurement invariance (i.e. weak-form invariance), taking account of metric and configural invariance while ignoring matters of scalar invariance (i.e. strong-form invariance) (Meredith, 1993). Hence, while there is preliminary evidence that PSM is applicable across sectors in China, this claim needs to be substantiated further.

A number of studies have shown a relationship exists between PSM and individual employee outcomes (e.g. commitment to the organisation, intention to remain with the organisation, citizenship behaviour, affective commitment and self-reported performance), although debate over the nature of the relationship continues (Ritz et al., 2016). Vandenabeele (2007) outlined both a direct self-selection and motivational relationship between PSM and employee behaviour, and an indirect relationship that relies upon the ability of the organisation to provide employees with an opportunity to fulfil their altruistic and public service values. In China, PSM has been studied as a predictor of job preferences in samples of Chinese students (Liu et al., 2008, Liu and Tang, 2011). Results indicate that only the self-sacrifice dimension was positively associated with public sector employment preferences, indicating that employees with high PSM may not always self-select to work in the public sector. PSM has however been found to be positively associated with performance in a sample of public sector employees (Xiaohua, 2008). Therefore, questions still remain regarding the relationship between PSM and employee outcomes in China, and whether this relationship differs between the public and private sectors.

Finally, organisations across the globe face a changing workforce as a new generation of millennial employees enters the job market. In particular, in the public sector organisations struggle to adapt to the expectations of younger employees. For example, Canadian millennials give a strong weight to work life balance and opportunity to contribute to society, and less so on material rewards (Ng and Gosset, 2013). "Fostering opportunities that are 
desirable to all employees may be a challenge, if younger and older employees value different work opportunities” (Ertas, 2013, p. 405).

In summary, in this paper we provide initial findings on whether employees with high PSM levels are more likely to perform better or retain membership of an organisation regardless of the sector they are employed in or their age. More specifically, in this paper we are interested in three aspects of PSM. First, we contribute to the debate vis-à-vis the ability of researchers to apply the PSM construct in the public and private sectors, using independent samples from one municipal district of China. Second, we compare across both sectors the relationship between PSM and the workplace outcomes self-reported performance and intention to leave. Third, we account for the changing demographics in the work environment by presenting a separate analysis on age.

\section{Measuring the level of PSM across sectors}

Although the majority of research on PSM focuses on applying some variant of the Perry (1996) measure to public sector workers, there is recognition that PSM is a concept that can be applied within other sectors. PSM is an individual-level concept (Brewer and Selden, 1998, Brewer et al., 2000, Pandey et al., 2008) and is not the preserve of the public sector. The concept may be applied to any sector, including the for-profit private sector, where employees are involved in the provision of public services (Steen, 2008).

Individuals with a high level of PSM may be expected to self-select into the public sector, as by its nature it provides a greater opportunity to engage in public service (Vandenabele, 2008). For this reason, Perry et al. (2010) maintains that PSM is grounded in the tasks of public service provision and should therefore be most prevalent in public sector organisations. Empirical findings that report a higher level of at least some dimensions of PSM amongst public and non-profit sectors, as opposed to the private sector, lend support to 
this proposition (Coursey et al., 2012, Word and Carpenter, 2013). Furthermore, it has found that intrinsic motivators, upon which PSM is reliant (Sung Min and Word, 2012), is of more importance to public sector workers than their private sector peers, where extrinsic motivators have greater priority (Anderfuhren-Biget et al., 2010).

It is assumed that the public sector is different from the private sector in terms of mission (value-creation versus profit-maximisation), role of stakeholders (multiple versus shareholder) and outcomes (public service versus shareholder value) (Lee, 2012). However, this clear sectoral divide has been undermined in recent decades by the introduction of new public management principles to the public sector, the outsourcing of public services to private corporations, and the increased awareness amongst private sector firms of their corporate social responsibility. As a result the definition of public service has been broadened to include all forms of employment that serves the community, and not just those employed by the government directly (Moutlon and Feney, 2011). Furthermore, as pointed out by Taylor (2008), while many public sector enterprises have a mission to serve the public interest, their governance (i.e. complex procedures and processes) and ambiguous objectives can hinder their ability to effectively achieve this mission. As a result of the above, the characteristics of the public sector that attract high PSM individuals may become blurry (Hinna, Homberg, Scarozza \& Verdini, 2019). Many potential employees with a high level of PSM may choose instead to take up a position in private sector organisations involved in public service provision.

A number of studies have investigated the applicability of Perry's PSM measure in the not-for-profit sector (Sung Min and Word, 2012, Word and Carpenter, 2013). These studies have shown that the PSM sub-dimensions, with the exception of attraction to public policy making, can be successfully applied to these other sectors as they are predominantly concerned with public service provision. Taylor (2010) did attempt to apply a number of 
items similar to those found in the Perry measure across a sample of public, private and nonprofit sectors in Australia. Although limited to a comparison of means across groups, Taylor's findings indicate the level of PSM is strongest amongst non-profit sector and public sector employees. Similar results have been found in a Chinese context by Liu et al. (2011) in relation to two dimensions of PSM. However, only Liu et al. (2012) provide some statistical evidence that the construct PSM or the measure used for it can be applied equally in the context of different sectors. Thus, after investigating the invariance of the PSM measure across both the public and private sectors, we hypothesize:

Hypothesis 1: Public sector employees display higher PSM levels than private sector employees.

\section{Comparing the outcomes of PSM across sectors}

Generally, PSM has been interpreted as a construct that leads to desirable behaviours inside organizations (Vogel et al., 2016, Homberg et al., 2017). Through the processes of recruitment, selection and socialisation within the organisation, those employees with a higher level of PSM can be expected to perform better or remain committed to public sector employers (Perry, 1996). Initially it was thereby believed that PSM had a direct relationship with performance related outcomes (Perry and Wise, 1990). However, attempts by empirical research to test the link between PSM and performance related attitudes and behaviour has generated mixed results, particularly where the focus is on work effort (Brewer, 2008; Giauque et al., 2013, Petrovsky and Ritz, 2014). Some have found a modest positive relationship with performance (Brewer et al., 2000, Naff and Crum, 1999), while others have found much less conclusive relationships (Alonso and Lewis, 2001). Kim (2005) and Vandenabeele (2009) found that the PSM-performance relationship is mediated by constructs such as job satisfaction, organisational citizenship behaviour and organisational commitment. 
Drawing on person-environment fit theory (Kristof, 1996), Bright (2007) and others focused on the mediating role of person-organisation fit. While Giauque et al. (2013) found that HRM practices are a stronger predictor of performance than PSM for a sample of over three thousand Swiss public sector workers. Recently, a meta-analysis summarized the available research on the PSM-performance link concluding “(...) while the PSM-performance relationship is statistically significant, PSM has a substantially small impact on performance” (Warren and Chen, 2013 p.469). The latter was found for both self-reported and revealed performance measures. These results have led many to conclude there is a role for mediating and moderating variables, particularly with regard to the work environment (Bright, 2013, Steijn, 2008).

Under this view, PSM can either stimulate or hinder work related outcomes, depending on the degree to which the organisation is seen to support the public interest (Wise, 2004). If the public sector is indeed more focused on promoting public welfare relative to the private sector, employees with a higher level of PSM can be expected to put more effort into their duties and remain with the organisation (Andersen and Kjeldsen, 2013, Steijn, 2008). The impact of PSM on outcomes will be enhanced when employees feel that their organisation's values are aligned with their own values in terms of altruism and public service (Bright, 2008). In a large scale study of 2,811 Danish employees, Anderson and Kjeldsen (2013) tested the relationship between PSM and job satisfaction across the public and private sectors. However, their results should no significant difference in the relationship across sectors.

In conclusion, where individual-based public service related needs are met by the organization there should be little incentive for the individual to resign and a greater level of work effort. Under the assumption that the public sector offers a greater opportunity to engage in the provision of public services relative to the private sector, we hypothesize: 
Hypothesis 2: PSM is negatively related to employee intention to leave the organization, with the relationship being more apparent in the public sector.

Hypothesis 3: PSM is positively related to self-reported work performance, with the relationship being more apparent in the public sector.

\section{Changing Demographics}

With the inflow of the millennial generation to the job market, HRM and management practices are assumed to change significantly in order to respond to their preferences (Montgomery and Ramus, 2011). On the one hand there is the assumption that younger workers have different attitudes, preferences and work values compared to their older colleagues (Smola and Sutton, 2002, Lyons et al., 2007, Krahn and Galambos, 2014). On the other hand, the debate by now also suffers from a number of stylized facts that have found little empirical support (for review see Parry and Urwin, 2011). As Lyons and Kuron (2013) state in their review of generational differences at work, "Evidence to date is fractured, contradictory and fraught with methodological inconsistencies that make generalizations difficult”.

With regards to PSM, for example, Asseburg and Homberg (2018) show that German students with high PSM levels put an equally high preference on extrinsic rewards as on intrinsic rewards. In a study of work values of Chinese employees, Wang et al. (2010) fail to find evidence of age related effects on work values. Nonetheless, age is frequently used as a control variable in PSM studies, and Pandey and Stazyk (2008) summarize a small set of findings on this relation claiming that the evidence is consistent with a linear relationship. In simple terms, older individuals tend to be more altruistic and hence also tend to show higher PSM levels. Hence when studying the relation between PSM, performance and turnover intentions it is useful to take a more detailed look at age differences, as the debate is not yet 
settled. Due to the varying results in the generational differences literature we do not present a separate hypothesis here, but highlight the necessity to investigate potential differences arising from varying age groups in our sample.

\section{Method}

\section{Data collection and measures}

The analysis in this paper is based on two independent survey panels. Both surveys were distributed in a paper format during the summer of 2013 and Table 1 provides descriptive statistics for each panel. The first panel consists of 220 usable responses received from public sector employees in the municipal district of Changsha, China. The second panel consists of 260 usable responses received from private sector employees undertaking a MBA course at a university in the Changsha district. Initially, 273 and 293 paper surveys were distributed to public and private sector workers respectively and responses were collected by way of drop-boxes. The final response rate was 81 per cent for the public sector panel and 89 per cent for the private sector panel.

\section{Insert Table 1 here}

The descriptive data shows the two panels are comparable along demographic lines. That said, the private sector panel has a somewhat older age profile, fewer people with a postgraduate qualification, and has a slightly higher proportion of males and single respondents. Data was also gathered on the grade and department of public sector respondents, with a majority (59 per cent) belonging to less senior grades (office clerk or staff members) and being employed directly by the city or provisional government (69 per cent).

This study used pre-existing measures and a seven-point scale for each variable; Table 
2 provides a full list of items. Many studies have reported issues with the measure for PSM created by Perry (1996). In particular, concerns have been raised about the validity and substantive fit of the attraction to public policy making sub-dimension (Kim, 2009a, Ritz and Waldner, 2011). These concerns prompted Kim (2009b) to develop an alternative measure for attraction to public policy, which utilises positively worded items and emphasises an interest in public policy as opposed to a desire to be actively involved in policy creation. For this reason, and given that Kim's measure for attraction to public policy can feasibly be applied to both the public and private sector, we utilise it in this study.

Employee performance was measured using a four-item scale taken from Babin and Boles (1998). We explicitly acknowledge that this is a measure of self-rated performance, which is a limitation of this study. Nonetheless, the discussion about performance measures is on-going and also non-self-rated measures have their downsides (Alonso and Lewis, 2001). The final outcome variable intention to leave is measured using a three-item measure taken from Boshoff and Allen (2000).

\section{Analysis method}

We use structural equation modelling (SEM) conducted using AMOS in our analysis. Before a meaningful discussion of the latent variable means or regression coefficients can be carried out based upon the two panels, it is important to ensure the measurement instruments used are invariant (Chen et al., 2005). As a result the analysis adopted in this paper will follow a number of stages.

In the first stage of analysis we test for the equivalence of the PSM measuring instrument and theoretical construct across both panels. This test for multi-group invariance will use analysis of covariance in line with Jöreskog (1971) tradition. After establishing for both panels separately a baseline model representing the best fit for the data in terms of both parsimony and substantive meaningfulness, we apply equality constraints in a hierarchical 
order on various parameters. More specifically, we place equality constraints in consecutive order upon the measured item factor loadings, their intercept values and the second order factor loadings and compare the fit for each model using the chi-squared difference test. As this test is sensitive to both non-normality and sample size, it is often considered an overly restrictive test. We therefore also report the CFI, Gamma hat and RMSEA goodness of fit statistics (Cheung and Rensvold, 2002).

After testing for this strong form of factorial invariance, we will be in a position to test for inter-group differences in the mean value for each unobserved latent variable. This will involve choosing one panel as a baseline group and statistically test for difference in latent means (Chen et al., 2005, Dimitrov, 2006).

In the second stage of the analysis we focus on the relationship between PSM and the outcome variables performance and intention to leave. After once again testing for invariance across factor loadings and structural covariances, we will compare the regression weights across both groups. A similar methodological approach as above was taken in comparing results across different age groups.

\section{Results}

\section{Preliminary analysis}

Table 2 provides descriptive statistics, factor loadings for each observed item. The factor loadings for the observed items measuring compassion are below the recommended 0.5 and their average loading is below the recommended 0.7. This undermines the validity of this measure, which has proved an issue for other researchers in the Chinese context (Liu and Tang, 2011). It was therefore decided to remove compassion as a measure in our analysis. The reliability (Cronbach's alpha) of each measure are also shown on Table 2 and was found to be in excess of the recommended 0.7 level for each measure (Nunnally and Bernstein, 
1994).

\section{Insert Table 2 here}

Issues around common method bias are of particular concern when survey instruments require respondents to provide self-reports on their personality or perceptions of work environment. To test for the presence of such method variance in our data, we employee the CFA marker technique as outlined by Williams et al. (2010). A two item measure for loyalty (see Table 2 for item description) was used as a marker variable, as it is both theoretically unrelated to at least one of the other substantive variables, but has a similar semantic content (Simmering et al., 2014). Furthermore, it was found that the marker does not exhibit a strong correlation with the other substantive variables in the model, including PSM (see table 2, PSM factor correlation = -0.075) (Lindell and Whitney, 2001). As shown in Table 3, by comparing the various nested models within this technique (Baseline, ModelC, Model-U and Model-R) using a change in chi-squared test, we find no evidence that the data is affected by common method bias.

\section{Insert Table 3 here}

\section{Cross-group PSM indicator analysis}

This section focuses on establishing whether or not the indicators being used to measure PSM represents the same construct in both response groups (Chen et al., 2005). We first conduct a confirmatory factor analysis (CFA) in each group separately to establish a measurement model that fits the data well in respect of parsimony and substantive meaningfulness. However, a similar or even identical measurement model in both groups 
only establishes configural invariance, and does not guarantee the equivalence of item measurements or the underlying theoretical construct. Thus, we also test for invariance across the measured item factor loadings, their intercept values and the second order factor loadings.

\section{Insert Table 4 here}

Table 4, models 1 to 4, show the change in chi-squared statistic for each nested model, along with a number of goodness-of-fit statistics (Gamma hat, CFI and RMSEA). Following the introduction of each parameter constraint no statistically significant change in the Chisquared value was found ( $\mathrm{p}>.05)$ (Milfont and Fischer, 2010). Establishing this strong from of measurement invariance is important where the intention is to compare mean values for the latent factors across groups. Thus, we can proceed with the assumption of scalar invariance and compare latent variable mean values for each PSM dimension across groups ( i.e. public and private sector).

\section{Insert Table 5 here}

Table 5 provides a comparison of the latent factor means across both sectors, with the private sector panel as base-group. Therefore the reported difference in mean estimates represents the degree to which mean values in the public sector differ from those found in the private sector. The statistical significance of this difference in means is assessed using the critical ratios and their respective p-values.

As would be expected, the level of self-sacrifice, attraction to public policy and commitment to public interest were on average found to be higher in the public sector. 
However, this difference is statistically significant in respect of only one dimension, commitment to public interest (Difference in mean estimate $=.228, \mathrm{p}<.05$ ). These findings are consistent with those of Liu et al. (2012), who also reported that while a statistically significant difference exists in relation to commitment to public interest, no such difference in self-sacrifice was observed. Where our results differ from those of Liu et al. is in relation to attraction to public policy, as their study adopted the PSM measure of Perry (1996) and therefore focused on attraction to public policy making. In conclusion, we find partial support for Hypothesis 1, which stated levels of PSM should be higher in the public sector.

\section{Structural invariance and comparison of estimates across groups}

We now wish to take a closer look at the relationship that exists between PSM and some workplace outcomes across both sectors. For the purposes of this initial study we focus on some of the more commonly assessed outcomes of PSM - employee performance and intention to leave. To enable us to compare the regression weights between PSM and these outcomes across both sectors we must first establish factor covariance invariance across both groups. Model 5 on Table 4 establishes a new baseline model with all the relevant variables included. As the subsequent models apply constraints first upon the factor loadings and then upon the factor covariances in the structural model, the results show that no statistically significant differences in the Chi-squared values are created by either set of constraints $(\mathrm{P}>.05)$. We have therefore established factor covariance invariance and can proceed in interpreting differences in the regression weights.

\section{Insert Table 6 here}

Table 6 shows the unstandardized regression weights $(\beta)$ for each of the relationships 
between PSM and the outcome variables ${ }^{1}$. The reported $\mathrm{z}$-score provides a test of statistical significant difference in regression values between the groups. The findings show that in both the public and private sectors there is a statistically significant positive relationship between PSM and self-reported employee performance $(\beta=0.385 / 0.339, \mathrm{P}<.05)$. Furthermore, there is no statistical evidence that the impact of PSM differs significantly between the two sectors. When looking at the relationship between PSM and intention to leave, it is only in the private sector that a significant negative relationship is found $(\beta=$ $0.275, \mathrm{P}<.05$ ). This is surprising, given that the existing literature would lead us to believe that it is in the public sector that PSM should have a greater impact on intention to leave. That said, we should also note that once again we could not find evidence of a statistically significant difference in this relationship between sectors.

These findings support research hypothesis 3, which expected PSM to be associated with higher levels of performance. However, in the case of the public sector, the findings fail to support hypothesis 2, which expected higher levels of PSM to be associated with lower intention to leave. The more interesting aspect of these results is the lack of statistically significant difference in terms of the impact PSM has on outcomes between the sectors. In the case of workers in the Changsha municipal district, whether an employee is found in the public or private sector, altruistic tendencies and a desire to serve public interest are associated with improved performance.

Finally, we investigate age effects. In order to so, we split the sample into millennials ( $n=151$, people born after 1983) and older individuals $(n=329)$. Results are displayed in panels 2 of tables 5 and 6 . Overall, we do not find any meaningful differences between the age groups, neither in mean PSM nor in the coefficients on performance or intention to leave.

\footnotetext{
${ }^{1}$ Measures for gender, age, education, job level and tenure were included as controls on the basis that previous research found them to be related to PSM (Bright 2005; Perry 1997; Pandey and Stazyk 2008; Naff and Crum 1999). These variables can also affect the costs associated with leaving a firm (Allen and Meyer, 1990) and performance outcomes (Ng and Feldman, 2010) and thus are also relevant from a theoretical point of view (Bernerth and Aguinis 2016). Findings are excluded from tables for purposes of clarity.
} 
Overall, these results support the stream of literature arguing that age related differences, especially generational work values, are less empirically relevant than we may believe. In particular, the finding on the not existing difference with regards to PSM among both groups is interesting. A common argument in studies based on western samples is that younger workers' high PSM is related to some ideal perceptions they hold towards public sector employers, but that this declines with tenure (Moynihan and Pandey 2007, Jensen and Vestergaard, 2017) due to a so called reality-shock (Kjeldsen and Jacobsen, 2012). Hence our results put into question if the same 'shock' logic holds in China.

\section{Discussion}

There have been a number of studies that set out to compare the level of PSM found in the public sector with that found in other sectors (e.g. not-for-profit, voluntary and private sectors). However, very few of these existing studies have applied statistical testing to ensure the concept of PSM or the measures used for it operate in the same way in different contexts. This paper uses two independent samples taken from the private and public sectors in a municipal district of China to provide some initial findings in this area. More specifically, the paper set out to test if the four-dimension theoretical construct for PSM is the same in each sector, identify any differences in mean values for each dimension and to examine differences regarding the relationship between PSM and workplace outcomes. It further focused on potential differences arising from changing demographical profiles of the workforce, in particular age effects.

Our findings show that in the Chinese context only three of the four PSM dimensions could be reliably measured, as found in previous research (Liu et al., 2008). The three dimensions examined were found to operate in a similar way in both sectors. Hence, our results are consistent with those presented by Liu et al. (2012) with regards to the 
applicability of PSM across sectors in China. Additionally, this provides support for the ability of researchers conducting comparisons between sectors using measures based upon Perry’s original 1996 measure. It would be recommended that any future studies that attempt to conduct cross-sector comparisons undertake a similar procedure of multi-group invariance testing before proceeding to interpret observed differences.

Our initial findings also highlight some issues that should be of concern to researchers in the area of PSM and provide grounds for future research. Firstly, existing PSM literature would lead us to believe that the mean level of PSM should be higher in the public sector than in the private sector. However, at least in the context of the Changsha Municipal District of China, we found evidence of just one dimension (attraction to public policy) that has a statistically higher mean value in the public sector. The predominant social, cultural and organisational norms in China may help explain these findings to some extent. The Chinese public service was founded by the Chinese Communist Party (CCP) on the Confucian principles of unselfishness, impartiality and fairness. Since China's adoption of the civil service system since 1993, the level of political involvement in the sector and remains of the old Cadre system means those who work in the sector often find their objectives integrated between service to the public and to the CCP. Furthermore, the public sector in China has suffered from widespread and endemic corruption, inefficiency and authoritarian organisational culture (Ko and Han, 2013).

As a result of these issues, many people who are attracted to work in the public sector do so for the status and job stability it brings, and not out of a desire to work in the public interest. It may therefore be unsurprising that levels of employee self-sacrifice and commitment to public interest are similar to those found in the private sector. While we accept the limited difference in the mean level of PSM identified in this study may be in part due to issues of regional context, these findings still provide grounds for further research. We 
would call for further cross-sector research to be conducted in other countries using measures based upon the Perry (1996) conceptualisation to establish if there truly is a significant difference in the mean values for each dimension. These findings also suggests that PSM is an issue not just for the management of public sector organisations, but should also be taken into account by private sector management involved in the provision of public services. Just as PSM has done much to move public sector management beyond principles based on public choice theory (i.e. self-interested agents), our findings would indicate that private sector workers are also likely to be motivated by a desire to serve their community and the wider public good.

Secondly, while we found PSM has a significant impact on self-reported employee performance, we found the relationship does not differ significantly between sectors. This finding appears to refute existing theory that it is in the public sector that employees are provided with the opportunity to act upon their desire to serve their community. These findings may be partly explained by the Chinese context in which they were found. It is not only in respect of the public sector that China has marked differences from the norms found in many Western cultures. Private sector organisations are also subject to considerable political intervention in China. Furthermore, Confucian principles such as humanity, righteousness and integrity, alongside loyalty, ritual and respect for authority also play a role in shaping the organisational culture of private sector organisations in China. It may therefore not be surprising to find that PSM has a greater effect on outcomes in the private sector, as these are concepts are just as applicable to the Chinese private sector as to its public sector. These again are findings that require further research but indicate that selecting employees with a high level of PSM can offer managers in the private sector just as much opportunity to enhance employee performance and retention as in the public sector.

Finally, we find that age differences do not matter. This has two implications. On the 
one hand it supports research arguing PSM develops in early years through education, and family socialization (Perry et al., 2008) and then remains rather stable (Vogel and Kroll, 2016). On the other hand, it may encourage HR developers to look very carefully at the preferences of their particular employees instead of resorting to stereotypical assumptions about age and generational cohorts.

We must however draw attention to the limitations faced by this research. Firstly, the relatively small sample used in this study raises legitimate concerns regarding the degree to which generalisations can be drawn regarding the wider Chinese economy or internationally. Nonetheless, the sample size is in line with, and even slightly larger than in previous research on PSM in China (Liu, 2009, Liu et al., 2008, Liu and Tang, 2011). Secondly, the measures we adopt in the study are self-reported and may be subject to biases arising from tendencies to exaggerate or provide responses that are deemed socially desirable. The latter is a particular concern in China, where tendencies to provide answers that are in line with what your boss or the survey administrator would wish to hear is a concern. Measures such as anonymity for respondents, voluntary participation and allowing respondents to complete their survey in private and in their own time were taken to reduce the likelihood of such biases arising. Post-hoc testing using Williams et al. (2010) CFA marker technique also failed to detect any issues with bias arising from common method variance.

\section{Funding}

This research was supported by 'the research fund for international young scientists' under the National Natural Science Foundation of China (project code: 71250110548).

\section{References}

Alonso, P. \& Lewis, G. B. (2001). "Public Service Motivation and Job Performance: Evidence from the Federal Sector", American Review of Public Administration, Vol. (31) No.(4), 363-380. 
Anderfuhren-Biget, S., Varone, F., Giauque, D. \& Ritz, A. (2010). "Motivating Employees of the Public Sector: Does Public Service Motivation Matter?", International Public Management Journal, Vol. (13) No.(3), 213-246.

Andersen, L. B. \& Kjeldsen, A. M. (2013). “Public Service Motivation, User Orientation, and Job Satisfaction: A Question of Employment Sector?", International Public Management Journal, Vol.(16) No.(2), 252-274.

Asseburg, J. \& Homberg, F. (2018). "Public Service Motivation or Sector Rewards? Two Studies on the Determinants of Sector Attraction", Review of Public Personnel Administration, Vol. (OnlineFirst).

Babin, B. J. \& Boles, J. S. (1998). "Employee Behaviour in a Service Environment: A Model and Test of Potential Differences Between Men and Women", Journal of Marketing, Vol. (62) No.(2), 7791.

Bernerth, J.B. \& Aguinis, H. (2016). "A Critical Review and Best-Practice Recommendations for Control Variable Usage", Personnel Psychology, Vol.(69) No.(1), 229-285.

Boshoff, C. \& Allen, J. (2000). "The Influence of Selected Antecedents on Frontline Staff's Perception of Service Recovery Performance", International Journal of Service Industry Management, Vol. (11) No.(1), 63-90.

Brewer, G. A. \& Selden, S. C. (1998). "Whisle Blowers in the Federal Civil Service: New Evidence of the Public Service Ethic", Journal of Public Administration Research \& Theory, Vol. (8) No.(3), 413-440.

Brewer, G. A., Selden, S. C. \& Facer li, R. L. (2000). "Individual Conceptions of Public Service Motivation", Public Administration Review, Vol. (60) No.(3), 254-264.

Bright, L. (2005). "Public Employees With High Levels of Public Service Motivation Who Are They, Where Are They, and What do They Want?", Review of Public Personnel Administration, Vol. (25) No.(2), 138-154.

Bright, L. (2007). “Does Person-Organization Fit Mediate the Relationship Between Public Service Motivation and the Job Performance of Public Employees?", Review of Personnel Administration, Vol.(27) No.(4), 361-379.

Bright, L. (2008). "Does Public Service Motivation Really Make a Difference on the Job Satisfaction and Turnover Intention of Public Employees?", American Review of Public Administration, Vol.(38) No.(2), 149-166.

Bright, L. (2013). "Where Does Service Motivation Count the Most in Government Work Environment? A Preliminary Empirical Investigation and Hypotheses", International Public Personnel Management, Vol.(42) No.(1), 5-26.

Chen, F. F., Sousa, K. H. \& West, S. G. (2005). "Testing Measurement Invariance of Second-Order Factor Models", Structural Equaltion Modelling, Vol. (12) No.(3), 471-492.

Cheung, G. W. \& Rensvold, R. B. (2002). "Evaluating Goodness-of-fit Indexes for Testing Measurement Invariance", Structural Equaltion Modelling, Vol. (9) No.(2), 233-255.

Coursey, D., Yang, K. \& Pandey, S. K. (2012). "Public Service Motivation (PSM) and Support for Citizen Participation: A Test of Perry and Vandenabeele's Reformulation of PSM Theory", Public Administration Review, Vol. (72) No.(4), 572-582.

Dimitrov, D. M. (2006). "Comparing Groups on Latent Variables: A Structural Equation Modeling Approach", Work Vol. (26) No.(2006), 429-436.

Ertas, N. (2013). "Formal and Informal Social Participation of Public, Non-Profit, and Private Employees", International Journal of Public Administration, Vol.(36) No.(8), 578-587.

Giauque, D., Anderfuhren-Biget, S. \& Varone, F. (2013). "Stress Perception in Public Organisations: Expanding the Job Demands-Job Resources Model by Including Public Service Motivation", Review of Public Personnel Administration, Vol. (33) No.(1), 58-83.

Hinna, A., Homberg, F., Scarozza, D. \& Verdini, V. (2019). "Public Service Motivation and Public Sector Employment Preference: Comparing Italian and British Students". Public Money \& Management, forthcoming. 
Homberg, F., Vogel, R. \& Weiherl, J. (2017). "Public Service Motivation and Continuous Organizational Change: Taking Charge Behaviour at Police Services", Public Administration, Vol. (Online first).

Jensen, U. T. \& Vestergaard, C. F. (2017). "Public Service Motivation and Public Service Behaviors: Testing the Moderating Effect of Tenure", Journal of Public Administration Research and Theory, Vol. (27) No. (1), 52-67.

Jöreskog, K. G. (1971). "Simultaneous Factor Analysis in Several Populations", Psychometrika, Vol. (36) No.(4), 409-426.

Kim, S. (2005). "Individual-Level Factors and Organizational Performance in Government Organizations", Journal of Public Administration Research \& Theory, Vol. (15) No.(2), 245261.

Kim, S. (2009a). "Revising Perry's Measurement Scale of Public Service Motivation", American Review of Public Administration, Vol. (39) No.(2), 149-163.

Kim, S. (2009b). "Does Person-Organisation Fit Matter in the Public Sector? Testing the Mediating Effect of Person-Organisation Fit in the Relationship Between Public Sector Motivation and Work Attitudes", Public Administration Review, Vol. (72) No.(6), 830-840.

Kim, S. (2012). "Testing the Structure of Public Service Motivation in Korea: A Research Note", Journal of Public Administration Research \& Theory, Vol. (19) No.(4), 839-851.

Kim, S., Vandenabeele, W., Wright, B. E., Andersen, L. B., Cerase, F. P., Christensen, R. K., Desmarais, C., Koumenta, M., Leisink, P., Bangcheng, L., Palidauskaite, J., Pedersen, L. H., Perry, J. L., Ritz, A., Taylor, J. \& De Vivo, P. (2013). "Investigating the Structure and Meaning of Public Service Motivation across Populations: Developing an International Instrument and Addressing Issues of Measurement Invariance", Journal of Public Administration Research \& Theory, Vol. (23) No.(1), 79-102.

Kjeldsen, A. M., \& Jacobsen, C. B. (2012). "Public Service Motivation and Employment Sector: Attraction or Socialization?", Journal of Public Administration Research and Theory, Vol. (23) No. (4), 899-926.

Ko, K. \& Han, L. (2013). "An Empirical Study on Public Service Motivation of the Next Generation Civil Servants in China", Public Personnel Management, Vol. (42) No.(2), 191-222.

Krahn, H. J. \& Galambos, N. L. (2014). "Work Values and Beliefs of 'Generation X' and 'Generation $Y^{\prime \prime \prime}$, Journal of Youth Studies, Vol. (17) No.(1), 92-112.

Kristof, A. (1996). "Person-Organization Fit: An Integrative Review of it Conceptualizations, Measurement, and Implications." Personnell Pshychology, Vol.(49) No.(1), 1-49.

Lee, Y.-J. (2012). "Behavioral Implications of Public Service Motivation: Volunteering by Public and Nonprofit Employees", Americal Review of Public Administration, Vol.(42) No.(1), 104-121.

Lindell, M. K. \& Whitney, D. J. (2001). "Accounting for Common Method Variance in Cross-Sectional Research Design", American Psychological Association, Vol.(86) No.(1), 114-121.

Liu, B.-C. \& Tang, T. L.-P. (2011). "Does the Love of Money Moderate the Relationship between Public Service Motivation and Job Satisfaction? The Case of Chinese Professionals in the Public Sector", Public Administration Review, Vol. (71) No.(5), 718-727.

Liu, B., Du, L., Wen, H. \& Fan, B. (2012). "Public Service Motivation of Public Versus Private Sector Employees in a Chinese Context", Social Behavior \& Personality, Vol. (40) No.(9), 1409-1418.

Liu, B., Zhang, X., Hu, Q. \& Du, L. (2015). "Validating the Construct of Public Service Motivation in For-profit Organizations: A Preliminary Study", Public Management Review, Vol. (17) No.(2), 262-287.

Liu, B. C. (2009). "Evidence of Public Service Motivation of Social Workers in China", International Review of Administrative Science, Vol. (75) No.(2), 349-366.

Liu, B. C., Tang, N. Y. \& Zhu, X. M. (2008). "Public Service Motivation and Job Satisfaction in China:An Investigation of Generalisability and Instrumentality", International Journal of Manpower, Vol. (29) No.(8), 684-699. 
Liu, B. C., Wen, H., Du, L. Y. \& Fan, B. Public Service Motivation of Public and Private Employees in Chinese Context: A Comparative Study. Service Systems and Service Management (ICSSSM) 8th International Conference, 2011. IEEE, 1-6.

Liu, B., Tang.L.-P., T. \& Yang, K. (2013). "When Does Public Service Motivation Fuel the Job Satisfaction Fire? The Joint Moderation of Person-Organization Fit and Needs-Supplies Fit", Public Management Review, Vol. (72) No.(6), 830-840.

Lyons, S., Duxbury, L. \& Higgins, C. (2007). "An Empirical Assessment of Generational Differences in Basic Human Values", Psychological Reports, Vol. (101), 339-352.

Lyons, S. \& Kuron, L. (2013). "Generational Differences in the Workplace: A Review of the Evidence and Directions for Future Research", Journal of Orgainzational Behaviour, Vol. (35) No.(S1), S139-S157.

Meredith, W. (1993). "Factor Analysis and Factorial Invariance", Psychometrika, Vol. (58) No.(4), 525543.

Milfont, T. L. \& Fischer, R. (2010). "Testing Measurement Invariance Across Groups: Application in Cross-Cultural Research", International Journal of Psychological Research, Vol. (3) No.(1), 111-121.

Montgomery, D. B. \& Ramus, C. A. (2011). "Calibrating MBA Job Preferences for the 21st Century", Academy of Management Learning \& Education, Vol. (10) No.(1), 9-26.

Moynihan, D. P. \& Pandey, S. K. (2007). "The Role of Organizations in Fostering Public Service Motivation", Public Administration Review, Vol. (67) No.(1), 40-53.

Naff, K. C. \& Crum, J. (1999). "Working for America: Does Public Service Motivation Make a Difference?", Review of Public Personnel Administration, Vol. (19) No.(4), 5-16.

Ng, E.S.W. \& Gossett, C.W. (2013). "Career Choice in Canadian Public Service", Public Personnel Management, Vol.(42) No.(3), 337-358.

Nunnally, J. C. \& Bernstein, I. H. 1994. Psychometric Theory, New York, McGraw Hill.

Pandey, S. K. \& Stazyk, E. C. (2008). "Antecedents and Correlates of Public Service Motivation". In: J.L., P. \& HONDEGHEM, A. (eds.), Motivation in Public Management: The Call of Public Service. Oxford Univ. Press, Oxford, 101-117

Pandey, S. K., Wright, B. E. \& Moynihan, D. P. (2008). "Public Service Motivation and Interpersonal Citizenship Behavior in Public Organizations: Testing a Preliminary Model", International Public Management Journal, Vol. (11) No.(1), 89-108.

Parry, E. \& Urwin, P. (2011). "Generational Differences in Work Values: A Review of Theory and Evidence", International Journal of Management Reviews, Vol. (13) No.(1), 79-96.

Perry, J. L. (1996). "Measuring Public Service Motivation: An Assessment of Construct Reliability and Validity", Journal of Public Administration Research \& Theory, Vol. (6) No.(1), 5-22.

Perry, J. L. (1997). "Antecedents of Public Service Motivation", Journal of Public Administration Research \& Theory, Vol. (7) No.(2), 181-197.

Perry, J. L., Brudney, J. L., Coursey, D. \& Littlepage, L. (2008). "What Drives Morally Committed Citizens? A Study of the Antecedents of Public Service Motivation", Public Administration Review, Vol. (68) No.(3), 445-458.

Perry, J. L., Hondeghem, A. \& Wise, L. R. (2010). "Revisiting the Motivational Bases of Public Service: Twenty Years of Research and an Agenda for the Future", Public Administration Review, Vol. (70) No.(5), 681-690.

Perry, J. L. \& Wise, L. R. (1990). "The Motivational Bases of Public Service", Public Administration Review, Vol. (50) No.(3), 367-373.

Petrovsky, N., \& Ritz, A. (2014). "Public Service Motivation and Performance: A Critical Perspective", Evidence-based HRM: a Global Forum for Empirical Scholarship, Vol. (2) No. (1), 57-79.

Ritz, A. Neumann, O. \& Brewer, G.A. (2016). "Public Service Motivation: A Systematic Literature Review and Outlook", Public Administration Review, Vol. (76) No.(3), 414-426. 
Ritz, A. \& Waldner, C. (2011). "Competing for Future Leaders: A Study of Attractiveness of Public Sector Organizations to Potential Job Applicants", Review of Public Personnel Administration, Vol. (31) No.(3), 291-316.

Simmering, M. J., Fuller, C. M., Richardson, H. A., Ocal, Y. \& Atinc, G. M. (2014). "Marker Variable Choice, Reporting, and Interpretation in the Detection of Common Method Variance: A Review and Demonstration", Organisational Research Methods, Vol. (18) No.(3), 473-511.

Smola, K. \& Sutton, D. (2002). "Generational Differences: Revisiting Generational Work Values for the New Millennium", Journal of Organizational Behavior, Vol. (23), 363-382.

Sung Min, P. \& Word, J. (2012). "Driven to Service: Intrinsic and Extrinsic Motivation for Public and Nonprofit Managers", Public Personnel Management, Vol. (41) No.(4), 705-734.

Steen, T. (2008). "Not a Government Monopoly: The Private, Nonprofit and Voluntary Sectors". In eds. J.L. Perry \& A. Hondeghem, Motivation in Public Management: The Call of Public Service. Oxford University Press: New York, 203-222.

Steijn, B. (2008). "Person-Environment Fit and Public Service Motivation", International Public Management Journal, Vol.(11) No.(1), 13-27.

Taylor, J. (2008). "Organizational Influences, Public Service Motivation and Work Outcomes: An Australian Study", International Public Management Journal, Vol. (11) No.(1), 67-88.

Taylor, J. (2010). "Public Service Motivation, Civic Attitudes and Actions of Public, Non-Profit and Private Sector Employees", Public Administration, Vol. (88) No.(4), 1083-1098.

Taylor, J. \& Taylor, R. (2011). "Working Hard for More Money or Working Hard to Make a Difference? Efficiency Wages, Public Service Motivation, and Effort", Review of Public Personnel Administration, Vol. (31) No.(1), 67-86.

Taylor, J. \& Westover, J. H. (2011). "Job Satisfaction in The Public Service: The Effects of Public Service Motivation, Workplace Attitudes and Work Relations", Public Management Review, Vol. (13) No.(5), 731-751.

Vandenabeele, W. (2007). "Toward a Public Administration Theory of Public Service Motivation", Public Management Review, Vol. (9) No.(4), 545-556.

Vandenabeele, W. (2009). "The Mediating Effect of Job Satisfaction and Organisational Commitment on Self-reported Performance: More Robust Evidence of the PSM-Performance Relationship", International Review of Administrative Science, Vol. (75) No.(1), 11-34.

Vogel, D. \& Kroll, A. (2016). "The Stability and Change of PSM-Related Values Across Time: Testing Theoretical Expectations Against Panel Data", International Public Management Journal, Vol. (19) No.(1), 53-77.

Vogel, R., Homberg, F. \& Gericke, A. (2016). "Abusive Supervision, Public Service Motivation, and Employee Deviance: The Moderating Role of Employment Sector", Evidence-Based HRM: a Global Forum for Empirical Scholarship, Forthcoming.

Wang, C. Y., Chen, M. H., Hyde, B. \& Hsieh, L. (2010). "Chinese Employees' Work Values and Turnover Intentions in Multinational Companies: The Mediation Effect of Pay Satisfaction", Social Behavior and Personality, Vol. (38) No.(7), 871-894.

Warren, D. C. \& Chen, L.-T. (2013). "The Relationship between Public Service Motivation and Performance". In: RINGQUIST, E. J. (ed.) Meta-Analysis for Public Management and Policy. Jossey-Bass, San Francisco, 442-474

Williams, L. J., Hartman, N. \& Cavazotte, F. (2010). "Method Variance and Marker Variables: A Review and Comprehensive CFA Marker Technique", Organisational Research Methods, Vol. (13) No.(3), 477-514.

Word, J. \& Carpenter, H. (2013). "The New Public Service? Applying the Public Service Motivation Model to Nonprofit Employees", Public Personnel Management, Vol. (42) No.(3), 315-336.

Xiaohua, L. (2008). "An Empirical Study on Public Service Motivation and the Performance of Government Employee in China", Canadian Social Science, Vol. (4) No.(2), 18-28. 
Table 1: Description of survey respondents

\begin{tabular}{|c|c|c|c|c|c|}
\hline Variable & Private & Public & Variable & Private & Public \\
\hline Total responses (n) & 220 & 260 & Gender (\%) & & \\
\hline Age (years) & 36.5 & 25.5 & Male & 38.5 & 22.7 \\
\hline $20-29$ & 46.9 & 41.4 & Female & 61.5 & 77.3 \\
\hline $30-39$ & 13.5 & 28.6 & Marital Status (\%) & & \\
\hline $40-49$ & 3.1 & 4.6 & Single & 28.1 & 22.7 \\
\hline $50+$ & & & Married & 70.9 & 77.9 \\
\hline Time with department & 4.3 & 6.0 & Grade (\%) & & \\
\hline Mean (years) & & & Office clerk & - & 28.6 \\
\hline Time with sector & 9.7 & 10.2 & Staff member & - & 30.0 \\
\hline Mean (years) & & & (Sub)stand science & - & 11.9 \\
\hline Qualification (\%) & 1.5 & 0.6 & (Deputy) county level & - & 29.5 \\
\hline High school & 5.8 & 4.5 & Department (\%) & & \\
\hline Junior college & 70.4 & 51.8 & County government & - & 10.5 \\
\hline Degree & 22.3 & 33.6 & City government & - & 34.5 \\
\hline Masters & 0 & 9.5 & Province government & - & 34.1 \\
\hline \multirow[t]{2}{*}{ Doctorate } & & & Public institution & - & 15.5 \\
\hline & & & Third Department & - & 5.5 \\
\hline
\end{tabular}


Table 2: Indicators of model variables and descriptive statistics

\begin{tabular}{|c|c|c|c|c|c|c|c|c|}
\hline \multirow[t]{2}{*}{ Variables } & \multirow[t]{2}{*}{ Code } & \multirow[t]{2}{*}{ Item } & \multicolumn{3}{|c|}{ Private } & \multicolumn{3}{|c|}{ Public } \\
\hline & & & $\mathbf{M}$ & SD & FL & $\mathbf{M}$ & SD & FL \\
\hline \multirow[t]{3}{*}{ Compassion } & $\mathrm{C} 1$ & I am often moved by the plight of the underprivileged. & 6.07 & 1.24 & .540 & 6.32 & 1.03 & .481 \\
\hline & $\mathrm{C} 2$ & It is difficult for me to contain my feelings when I see people in distress. & 5.32 & 1.99 & .515 & 5.85 & 1.74 & .374 \\
\hline & C3 & I often think about the welfare of people I do not know personally. & 4.40 & 1.58 & .642 & 4.96 & 1.64 & .697 \\
\hline \multirow{5}{*}{ Self-sacrifice } & $\mathrm{C} 4$ & I am often reminded by daily events how dependent we are on one another. & 5.83 & 1.33 & .596 & 5.94 & 1.36 & .537 \\
\hline & SS1 & Making a difference in society means more to me than personal achievements. & 4.60 & 1.57 & .855 & 5.00 & 1.49 & .799 \\
\hline & SS2 & Doing good deeds is definitely more important to me than doing well financially. & 4.54 & 1.67 & .823 & 4.93 & 1.61 & .773 \\
\hline & SS3 & I think people should give back to society more than they get from it. & 4.72 & 1.50 & .846 & 5.12 & 1.41 & .770 \\
\hline & SS4 & I am prepared to make enormous sacrifices for the good of society & 4.16 & 1.67 & .780 & 4.70 & 1.64 & .839 \\
\hline \multirow{3}{*}{$\begin{array}{l}\text { Attraction to public } \\
\text { policy }\end{array}$} & PP1 & I am interested in the creation of public programmes that are beneficial to my country... & 6.05 & 1.18 & .720 & 6.17 & 0.97 & .781 \\
\hline & PP2 & Sharing my views on public policies with others is attractive to me & 5.75 & 1.24 & .767 & 6.07 & 0.98 & 699 \\
\hline & PР3 & Seeing people get benefits from the public programmes I have been deeply involved... & 6.00 & 1.14 & .749 & 6.20 & 1.00 & .810 \\
\hline \multirow{4}{*}{$\begin{array}{l}\text { Commitment to } \\
\text { public interest }\end{array}$} & PI1 & I unselfishly contribute to my community. & 4.79 & 1.50 & .733 & 5.19 & 1.38 & .734 \\
\hline & PI2 & Meaningful public service is very important to me. & 5.82 & 1.27 & .853 & 6.01 & 1.03 & .706 \\
\hline & PI3 & I would prefer seeing public officials do what is best for the whole community... & 5.42 & 1.43 & .746 & 5.57 & 1.38 & .754 \\
\hline & PI4 & I consider public service my civic duty. & 5.84 & 1.30 & .767 & 6.06 & 1.16 & .676 \\
\hline \multirow[t]{3}{*}{ Intention to leave } & IL1 & I often think about resigning & 2.94 & 1.93 & .709 & 2.55 & 1.74 & .736 \\
\hline & IL2 & It would not take much to make me resign from this job & 3.66 & 1.99 & .543 & 3.15 & 1.96 & .653 \\
\hline & IL3 & I will probably be looking for another job soon & 3.38 & 1.99 & .710 & 2.59 & 1.85 & .800 \\
\hline \multirow[t]{4}{*}{ Performance } & $\mathrm{P} 1$ & I get along better with customers than most of my co-workers & 5.30 & 1.55 & .482 & 4.95 & 1.63 & .582 \\
\hline & $\mathrm{P} 2$ & My performance is in the top 10 per cent compared to my co-workers & 5.58 & 1.41 & .730 & 5.16 & 1.39 & .800 \\
\hline & P3 & I consistently deliver a better quality service than most of my co-workers & 5.79 & 1.12 & .898 & 5.35 & 1.21 & .916 \\
\hline & P4 & I go more out of my way to help customers than most of my co-workers & 5.76 & 1.17 & .797 & 5.54 & 1.17 & .808 \\
\hline \multirow{2}{*}{$\begin{array}{l}\text { Marker variable } \\
\text { (loyalty) }\end{array}$} & L1 & Represents the organisation favourable to outsiders & 3.02 & 1.86 & .980 & 3.38 & 1.93 & .954 \\
\hline & L2 & Actively promotes the organisation's products and services & 3.14 & 1.84 & .844 & 3.37 & 1.87 & .859 \\
\hline
\end{tabular}


Table 2 (continued): Indicators of model variables and descriptive statistics

Factor Correlation Matrix and Cronbach's Alpha

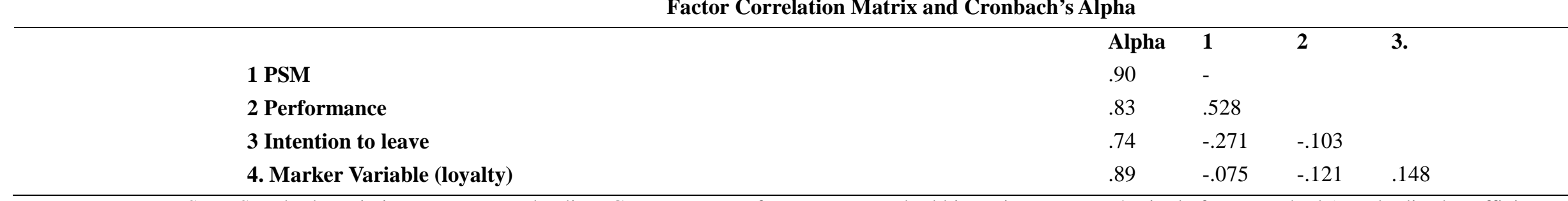

Note: $\mathrm{M}=$ Mean, SD = Standard Deviation, FL = Factor loading, CMB test = test for common method bias using Hermann’s single factor method (standardised coefficients without common latent factor - standardised coefficient with common latent factor) 
Table 3: Results of Williams et al. (2010) Marker Variable Analyses

\begin{tabular}{|c|c|c|c|c|c|}
\hline Model & $\chi^{2}$ & df & RMSEA & CFI & TLI \\
\hline CFA & 171.55 & 94 & .042 & .978 & .972 \\
\hline Baseline & 184.68 & 99 & .043 & .976 & .971 \\
\hline Method-C & 184.00 & 98 & .043 & .976 & .970 \\
\hline Method-U & 163.75 & 85 & .042 & .980 & .971 \\
\hline \multirow[t]{2}{*}{ Method-R } & 184.15 & 104 & .040 & .977 & .974 \\
\hline & $\Delta \mathrm{x}^{2}$ & $\Delta \mathrm{df}$ & & Critical Value at $\chi^{2} .050$ & \\
\hline Baseline Vs Method-C & 0.67 & 1 & & 3.84 & \\
\hline Method-C Vs Method-U & 20.25 & 13 & & 22.36 & \\
\hline Method-C Vs Method-R & 0.14 & 6 & & 12.59 & \\
\hline
\end{tabular}

Note: $\chi^{2}=$ Chi-squared, $\mathrm{df}=$ degrees of freedom, RMSEA = Root Mean Square Error of Approximation, CFI = comparative fit index, TLI = Tucker-Lewis coefficient, $\Delta=$ change in 
Table 4: Goodness of fit statistics for invariance tests

\begin{tabular}{|c|c|c|c|c|c|c|c|c|c|}
\hline Model description & $\chi^{2}$ & df & RMSEA & $\begin{array}{l}\text { Gamma } \\
\text { Hat }\end{array}$ & CFI & $\begin{array}{l}\text { Models } \\
\text { compared }\end{array}$ & $\Delta \chi^{2}$ & $\Delta$ df & $\begin{array}{c}\text { p- } \\
\text { value }\end{array}$ \\
\hline Model 1: Baseline model (PSM measure) & 154.16 & 82 & .043 & .961 & .978 & - & - & - & - \\
\hline Model 2: first order factor loadings constrained equal & 164.01 & 90 & .043 & .964 & .973 & $2 \& 1$ & 9.84 & 8 & .276 \\
\hline $\begin{array}{l}\text { Model 3: model } 2 \text { and intercept of measured variables } \\
\text { constrained equal }\end{array}$ & 164.14 & 92 & .041 & .965 & .973 & $3 \& 2$ & 9.97 & 10 & .443 \\
\hline $\begin{array}{l}\text { Model 4: model } 3 \text { and second order factor loadings constrained } \\
\text { equal }\end{array}$ & 156.81 & 84 & .043 & .962 & .972 & $4 \& 3$ & 2.65 & 2 & .266 \\
\hline $\begin{array}{l}\text { Model 5: Baseline model (PSM and other structural model } \\
\text { measures -Performance, Intention to leave) }\end{array}$ & 415.77 & 258 & .036 & .974 & .960 & - & - & - & - \\
\hline $\begin{array}{l}\text { Model 6: Factor loadings constrained equal (including second } \\
\text { order PSM factor loadings) }\end{array}$ & 432.08 & 271 & .035 & .974 & .959 & $7 \& 6$ & 16.32 & 13 & .232 \\
\hline Model 7: Model 6 and structural covariance constrained equal & 420.29 & 261 & .036 & .974 & .959 & $7 \& 6$ & 4.52 & 3 & .211 \\
\hline
\end{tabular}

Note: $\chi^{2}=$ Chi-squared, $\mathrm{df}=$ degrees of freedom, RMSEA = Root Mean Square Error of Approximation, CFI = comparative fit index, $\Delta=$ change in. 
Table 5: PSM dimensions' mean value comparison across groups

\begin{tabular}{lcccc}
\hline & Difference in mean estimate & S.E. & C.R. & p-value \\
\cline { 2 - 5 } Panel 1: Sector Comparison & & & & \\
Self-sacrifice & .220 & .119 & 1.85 & .064 \\
Attraction to public policy & .107 & .079 & 1.35 & .176 \\
Commitment to public interest & .228 & .107 & 2.12 & .034 \\
\hline Panel 2: Age-group Comparison & & & & \\
Self-sacrifice & .077 & .138 & 0.55 & .580 \\
Attraction to public policy & .101 & .083 & 1.22 & .221 \\
Commitment to public interest & .165 & .110 & 1.50 & .135 \\
\hline
\end{tabular}

Note: S.E.= standard error, C.R. $=$ critical ratio, base group for difference in latent variable means $=$ Private sector group (Panel 1) and millennials group (Panel 2). 
Table 6: Structural regression weight comparison across groups

\begin{tabular}{lccr}
\hline Relationship & $\boldsymbol{\beta}$-Private/Millennials & $\boldsymbol{\beta}$-Public/Older & z-score \\
\hline Panel 1: Sector Comparison & & & \\
\hline PSM - Intention to leave & $-0.275^{* *}$ & -0.046 & 1.525 \\
PSM - Performance & $0.385^{* * *}$ & $0.339^{* * *}$ & -0.410 \\
\hline Panel 2: Age-group Comparison & & & \\
PSM - Intention to leave & -0.129 & $-0.192^{*}$ & -0.464 \\
PSM - Performance & $0.249^{*}$ & $0.343^{* * *}$ & 0.683 \\
\hline
\end{tabular}

Note: ${ }^{*} \mathrm{p}<.05,{ }^{* *} \mathrm{p}<.01,{ }^{* * *} \mathrm{p}<.001, \beta=$ unstandardized coefficient. 
Figure 1: Model

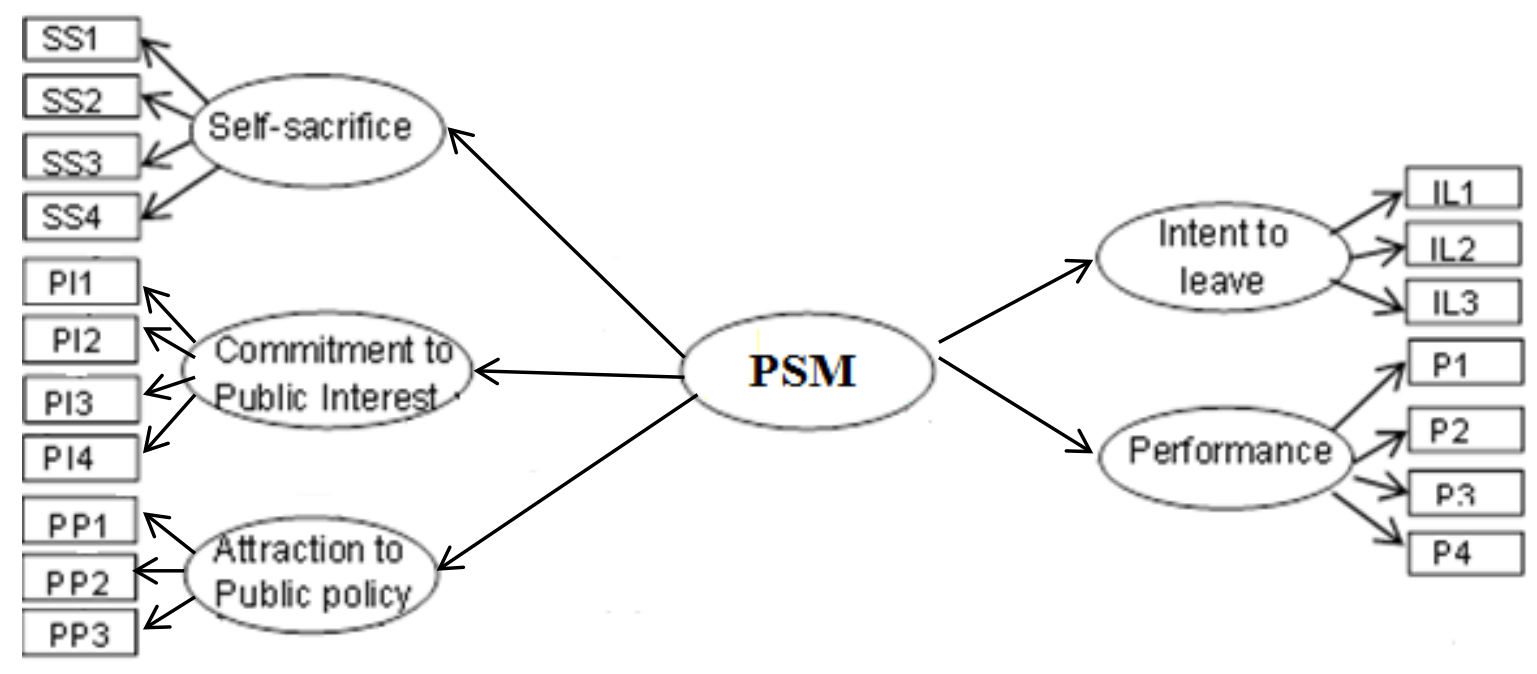

